\title{
Evaluation Of The Seismic Performance Of Masonry Buildings Of The Type "Gaioleiro", Lisbon (Portugal)
}

\author{
Nuno Mendes ${ }^{\mathrm{a}}$ and Paulo B. Lourenço ${ }^{\mathrm{b}}$ \\ ${ }^{a}$ PhD student, ISISE, University of Minho, Guimarães, Portugal. \\ nunomendes@civil.uminho.pt \\ ${ }^{b}$ Professor, ISISE, University of Minho, Guimarães, Portugal. \\ pbl@civil.uminho.pt
}

\begin{abstract}
This paper presents the numerical study that aims at the seismic evaluation of the performance of typical Portuguese "gaioleiro" buildings. The numerical modeling was performed with resource to a model of finite elements on 1:3 reduced scale and it was calibrated in agreement with experimental results obtained in the tests done in the LNEC 3D shaking table. With the purpose to define an adequate strategy for seismic performance evaluation nonlinear dynamical analysis with time integration and pushover analyses were carried out. In the dynamic analysis, each earthquake is composed by two uncorrelated artificial accelerograms compatible with design response spectrum of EC8. In the pushover analyses it was considered that the seismic action is simulated through a set of proportional horizontal forces to the mass of structure and to the $1^{\text {st }}$ vibration mode according with the direction in study.
\end{abstract}

Keywords: "Gaioleiro" buildings, seismic performance, nonlinear dynamic and static analyses.

\section{INTRODUCTION}

The study of the ancient masonry buildings has been limited. Only in the past few years this issue has been taken in account due, essentially, to the increase of the interest on the preservation of the built patrimony. Among this buildings there is a considerably quantity of residential buildings, originally built with insufficient earthquake resistance or none at all.

The most recent methods of collective seismic evaluation are based on the concept of representative construction of a certain typology for, with base on its individual evaluation, esteem the seismic performance of all buildings included in the typology.

In the present work it was studied the seismic performance of the "gaioleiro" type buildings (Fig. 1). This typology developed between the mid XIX century and beginning of the XX century, mainly in the city of Lisbon, where are still in use nowadays.

Typically, these buildings have 4 storeys high with walls in masonry and floors and roof in wood. The exterior walls are, usually, in rubble masonry with bonding mortar [1]. 
In the whole, the study includes two programs: an experimental and a numerical; developed, respectively, by LNEC (National Laboratory of Civil Engineering) and by University of Minho.
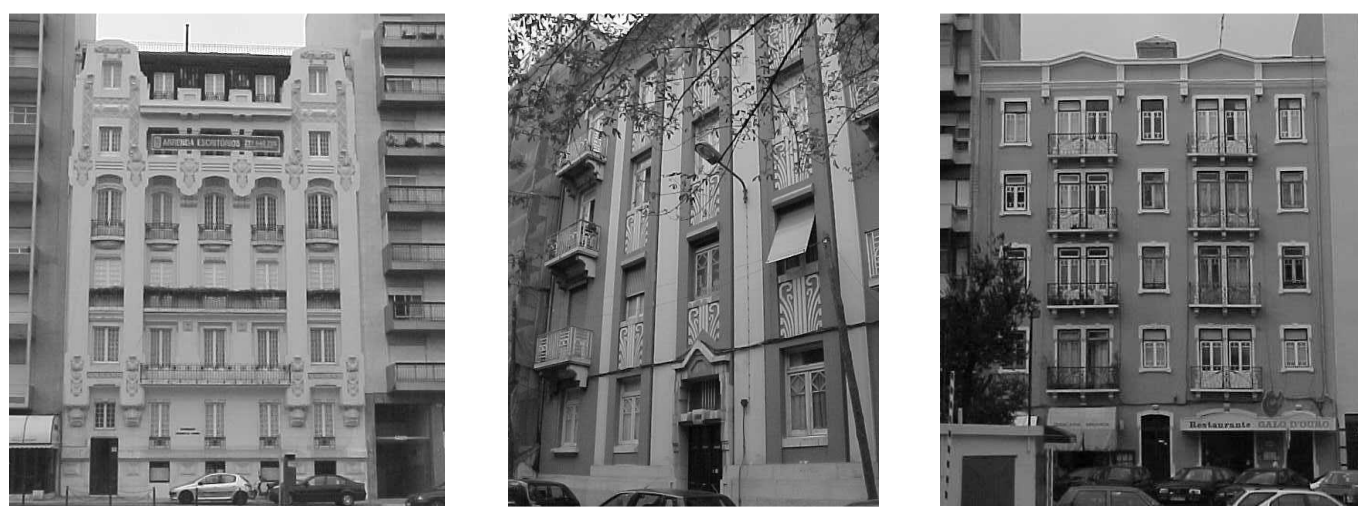

FIGURE 1. "Gaioleiros" buildings.

\section{DESCRIPTION OF THE EXPERIMENTAL MODEL}

The LNEC accomplished a set of tests in their shaking table, with purpose to study the seismic performance of this type of buildings, before and after strengthening [2]. For that, a prototype of isolated buildings was defined. This is constituted by four storeys, with an interstory height of $3.60 \mathrm{~m}$, two opposite facades with a percentage of openings equal to $28.6 \%$ of the facade area, two opposite walls with no openings, wood pavements and a gable roof.

Due to the size and payload capacity of the shaking table the experimental models were built to $1: 3$ reduced scale, in agreement with Cauchy law similitude. The relations for the different parameters in terms of scale factor are presented in Table 1.

TABLE 1. Scale factors of the Cauchy similitude law [3].

(where ${ }_{p}$ and ${ }_{m}$ designate prototype and experimental model, respectively)

\begin{tabular}{lcc}
\hline Parameter & Symbol & Scale factor \\
\hline Length & $\mathrm{L}$ & $\mathrm{L}_{\mathrm{p}} / \mathrm{L}_{\mathrm{m}}=\lambda=3$ \\
Elasticity modulus & $\mathrm{E}$ & $\mathrm{E}_{\mathrm{p}} / \mathrm{E}_{\mathrm{m}}=\lambda=1$ \\
Specific mass & $\rho$ & $\rho_{\mathrm{p}} / \rho_{\mathrm{m}}=\lambda=1$ \\
Area & $\mathrm{A}$ & $\mathrm{A}_{\mathrm{p}} / \mathrm{A}_{\mathrm{m}}=\lambda^{2}=9$ \\
Volume & $\mathrm{V}$ & $\mathrm{V}_{\mathrm{p}} / \mathrm{V}_{\mathrm{m}}=\lambda^{3}=27$ \\
Mass & $\mathrm{m}$ & $\mathrm{m}_{\mathrm{p}} / \mathrm{m}_{\mathrm{m}}=\lambda^{3}=27$ \\
Displacement & $\mathrm{d}$ & $\mathrm{d}_{\mathrm{p}} / \mathrm{d}_{\mathrm{m}}=\lambda=3$ \\
Velocity & $\mathrm{v}$ & $\mathrm{V}_{\mathrm{p}} / \mathrm{v}_{\mathrm{m}}=\lambda=1$ \\
Acceleration & $\mathrm{a}$ & $\mathrm{a}_{\mathrm{p}} / \mathrm{a}_{\mathrm{m}}=\lambda^{-1}=1 / 3$ \\
Weight & $\mathrm{W}$ & $\mathrm{W}_{\mathrm{p}} / \mathrm{W}_{\mathrm{m}}=\lambda^{3}=27$ \\
Force & $\mathrm{F}$ & $\mathrm{F}_{\mathrm{p}} / \mathrm{F}_{\mathrm{m}}=\lambda^{2}=9$ \\
Moment & $\mathrm{M}$ & $\mathrm{M}_{\mathrm{p}} / \mathrm{M}_{\mathrm{m}}=\lambda^{3}=27$ \\
Stress & $\sigma$ & $\sigma_{\mathrm{p}} / \sigma_{\mathrm{m}}=\lambda=1$ \\
Strain & $\varepsilon$ & $\varepsilon_{\mathrm{p}} / \varepsilon_{\mathrm{m}}=\lambda=1$ \\
Time & $\mathrm{t}$ & $\mathrm{t}_{\mathrm{p}} / \mathrm{t}_{\mathrm{m}}=\lambda=3$ \\
Frequency & $\mathrm{f}$ & $\mathrm{f}_{\mathrm{p}} / \mathrm{f}_{\mathrm{m}}=\lambda^{-1}=1 / 3$ \\
\hline
\end{tabular}


The walls of the experimental model were simulated by a compacting concrete, previously study to simulate the typical behavior of the original masonry walls.

In the construction of the pavements, MDF panels connected to a set of wood joists oriented in the direction of the smaller span were used. The panels were cut in rectangles of $0.57 \mathrm{~m} \times 0.105 \mathrm{~m}$ and stapled to the joists with broken joints of approximately $1 \mathrm{~mm}$, with purpose to simulate pavement flexibility.

Finally, the experimental model didn't include the roof due to the difficulties in their construction in the laboratory.

In the Fig. 2 is presented the experimental model resulting from the scale factor.

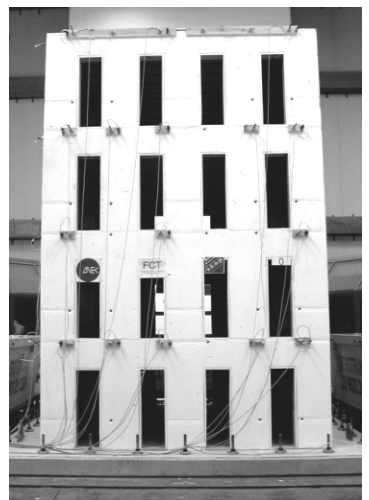

(a)

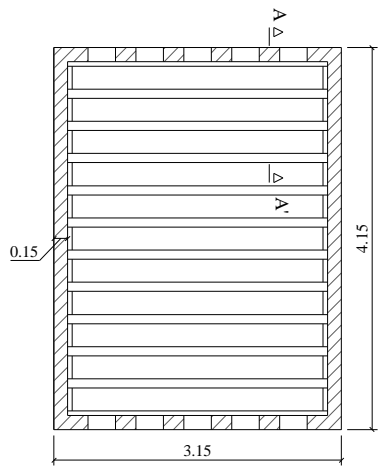

(c)
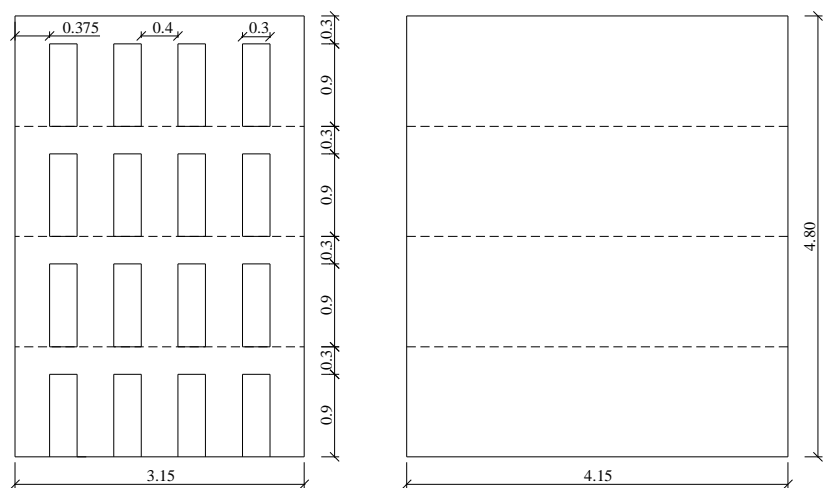

(b)

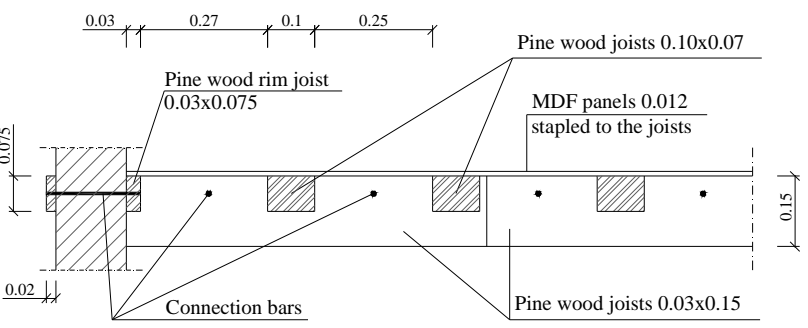

(d)

FIGURE 2. Experimental model (dimensions in meters): (a) general view; (b) geometrical proprieties; (c) plant; (d) pavements (section AA').

\section{DESCRIPTION OF THE NUMERICAL MODEL}

The numerical model was accomplished in the Elements Finites software Diana [4], by using shell elements for the simulation of the walls and MDF panels, and three dimensional beam elements in the simulation of the wood joists, based on the theory of Mindlin-Reissner (Fig. 3). In the supports, only the translation degrees of freedom in the base were restrained.

Concerning to the geometrical proprieties, the numerical model was accomplished to the 1:3 reduced scale as the experimental model (Fig. 2).

In the connection between the pavements and the masonry walls only the translation degrees of freedom were considered compatibles. 


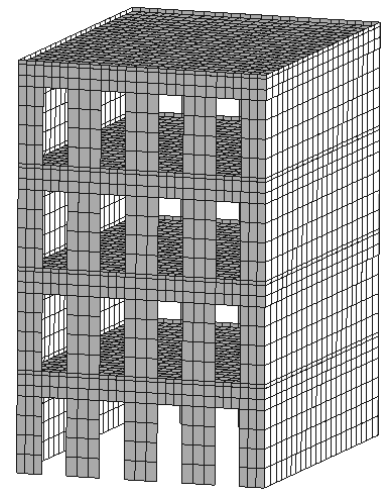

(a)

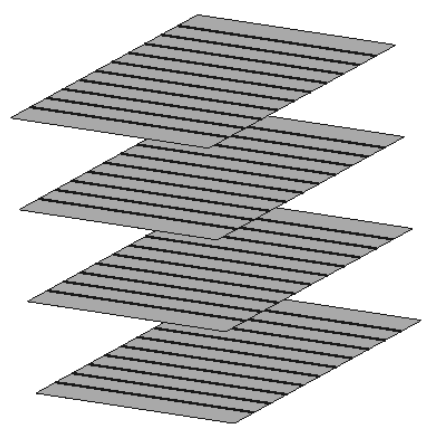

(b)
Proprieties of the finite elements mesh :

- 5816 finite elements:

- 1081 beams elements;

- 4736 shell elements;

- 75880 degrees of freedom;

- 15176 nodes.

In the calibration of the numerical model the vibration modes and others quantities measured in the tests were used [5].

The Fig. 4 shows, in a global way, that the numerical model simulates correctly the damage existent in the experimental model with appropriate connection between pavements and walls, where the facade damage concentration in the $4^{\text {th }}$ floor is highlighted.

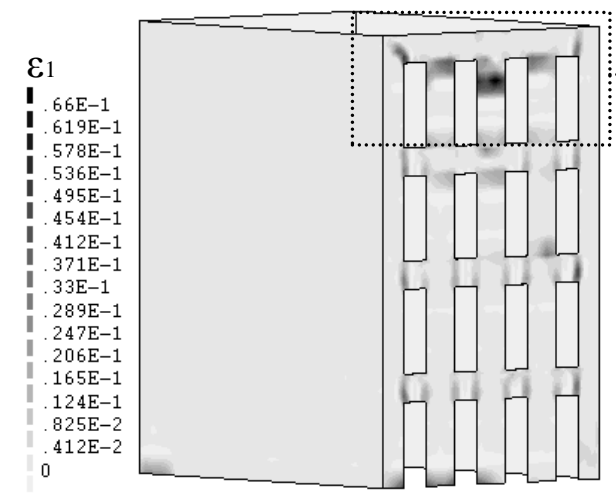

(a)

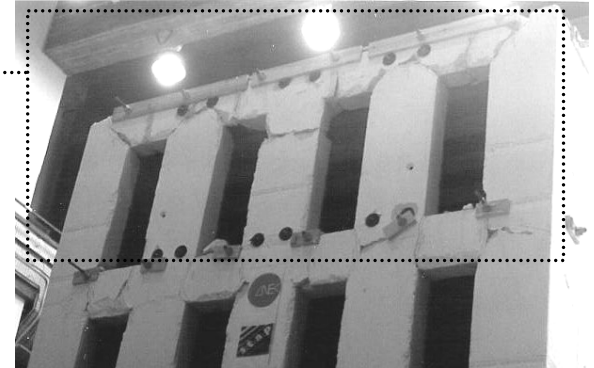

(b)

FIGURE 4. Damage comparison between the model: (a) numerical; and (b) experimental.

As result of the calibration process it was obtained the material proprieties of the numerical model. However, it was aim of alterations, namely in what concern to the total mass of the structural system. In this way, the model used in the numerical study included, besides the self weight of the structural elements considered in the experimental model, the live load and the self weight of the partitions walls, claddings and roof. These additional actions were considered, indirectly, at the level of the floors with resource to the MDF panel's specific mass increase.

In the Table 2 presents the material proprieties associated to the elastic linear behavior. The reduced value of the MDF panel's young's modulus is due to the pavements constructive process (broken joints).

The Fig. 5 shows the first vibration modes, in the transversal and longitudinal directions. 
TABLE 2. Materials elastic linear proprieties of the numerical model.

\begin{tabular}{lccc}
\hline & $\begin{array}{c}\text { Young's modulus } \\
{\left[\mathbf{N} / \mathbf{m m}^{2}\right]}\end{array}$ & $\begin{array}{c}\text { Poisson's } \\
\text { ratio }\end{array}$ & $\begin{array}{c}\text { Specific mass } \\
{\left[\mathbf{K g} / \mathbf{m}^{\mathbf{3}}\right]}\end{array}$ \\
\hline Walls & 779 & 0.2 & 1910 \\
MDF panels $1^{\text {st }}-3^{\text {rd }}$ floor & 240 & 0.3 & 5427 \\
MDF panels $4^{\text {th }}$ floor & 240 & 0.3 & 4047 \\
Wood joist & 12000 & 0.3 & 580 \\
\hline
\end{tabular}

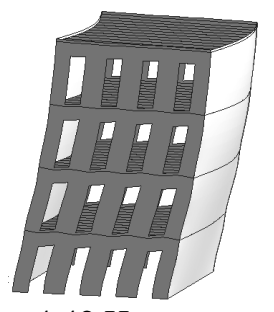

$4.42 \mathrm{~Hz}$

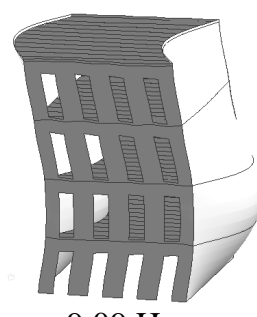

$9.09 \mathrm{~Hz}$

(a)

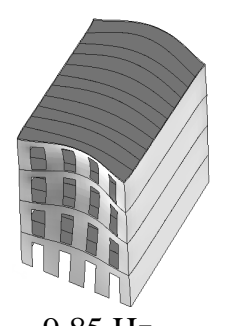

$9.85 \mathrm{~Hz}$

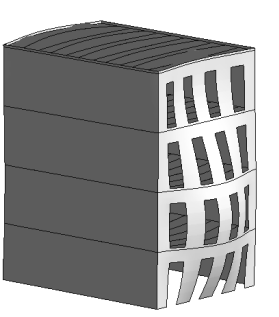

$14.86 \mathrm{~Hz}$

(b)

FIGURE 5. First vibration modes in the: (a) transversal direction; (b) longitudinal direction.

In the numerical model only the nonlinear behavior of the masonry walls was considered, based on the constitutive model of total strains, usually knows by Total Strain Crack Model. It was accessed in their definition, a parabolic stress-strain relation for compression, where the compressive strength, $f_{c}$, is equal to $779 \mathrm{~N} / \mathrm{mm}$ and the respectively fracture energy, $G_{c}$, is equal to $1.25 \mathrm{~N} / \mathrm{mm}^{2} \mathrm{~mm}$. In tensile, an exponential tension-softening followed by a linear tension-stiffness was accessed, where the tensile strength, $f_{t}$, is equal to $125 \mathrm{~N} / \mathrm{mm}^{2}$ and the fracture energy, $G_{t}$, is equal to $0.125 \mathrm{~N} / \mathrm{mm}^{2} \mathrm{~mm}$. The crack bandwidth, $h$, was determined in function of element area, $A$ (Equation 1). In the shear behavior, the shear retention factor equal to 0.001 was accessed.

$$
h=\sqrt{A} .
$$

The damping, $\underline{C}$, was simulated with resource to the viscous damping of Rayleigh, which presents as a linear combitaion between the mass, $\underline{M}$, and of stiffnes, $\underline{K}$, matrixes (Equation 2). The constantes $\alpha$ (2.18) and $\beta$ (0.00044) were determinated with resource throught the results obtained in the dynamic indentification.

$$
\underline{C}=\alpha \underline{M}+\beta \underline{K}
$$

\section{NONLINEAR DYNAMICAL ANALYSIS}

The nonlinear dynamical analysis with time integration was done with resource to 3 earthquakes, composed, each one, for 2 uncorrelated artificial accelerograms.

The artificial accelerograms were generated with resource to EC8 design response spectrum of the type 1 [6], for zone of Lisbon $\left(a_{g}=1.5 \mathrm{~m} / \mathrm{s}^{2}\right)$, with damping coefficient, $\xi$, equal to $4.3 \%$ (estimated in the dynamic identification) and a type $\mathrm{A}$ soil. These present, on 1:3 reduced scale, a total duration of $6 \mathrm{~s}$, which $3.33 \mathrm{~s}$ correspond to the intense phase, and a $P G A$, on average, equal to $4.51 \mathrm{~m} / \mathrm{s}^{2}$. 
In the Fig. 6 is presented the maximum values of the tensile principal strains, $\varepsilon 1$, for the different earthquakes. Through this, it was verified that the facades in $4^{\text {th }}$ floor and the base of structure are the zones of largest damage concentration, where a high level of damage in the $4^{\text {th }}$ floor's piers is highlighted.

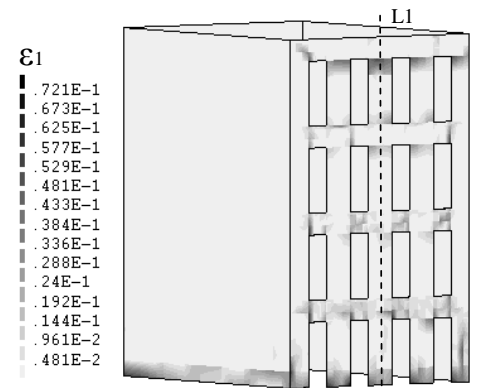

(a)

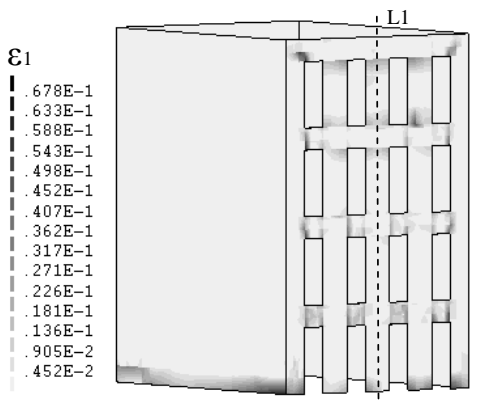

(b)

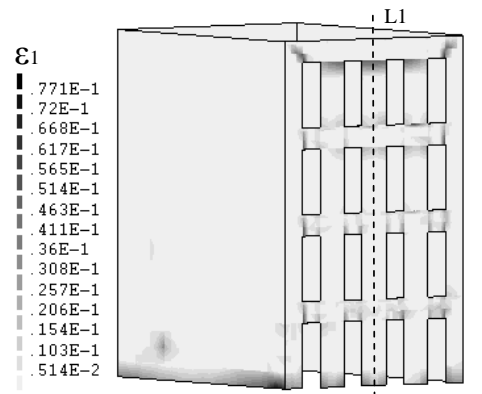

(c)

FIGURE 6. Tensile principal stains (outside surface): (a) earthquake 1; (b) earthquake 2;

(c) earthquake 3 .

Unlike to the typical structures of concrete, the analysis of results at the level of the floors isn't enough to identify correctly the zones of largest damage. Hence, the maximum displacement and the maximum drift in the alignment $L 1$, using all its nodes in the finite elements mesh, are presented in the Fig. 7. Through this representation is verified that the maximum displacement (about $16 \mathrm{~mm}$ ) take place in the $4^{\text {th }}$ floor pier and that the maximum drift (higher than $1 \%$ ) happen in $4^{\text {th }}$ floor and in the base.

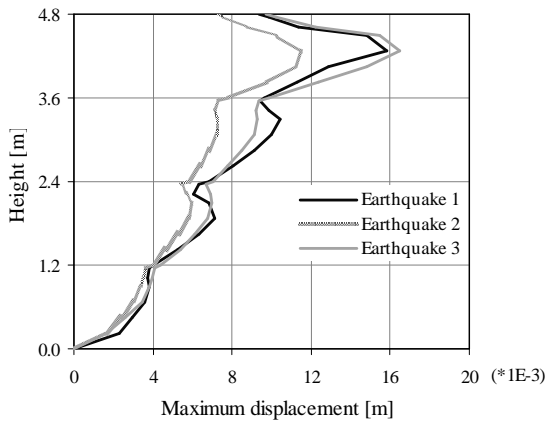

(a)

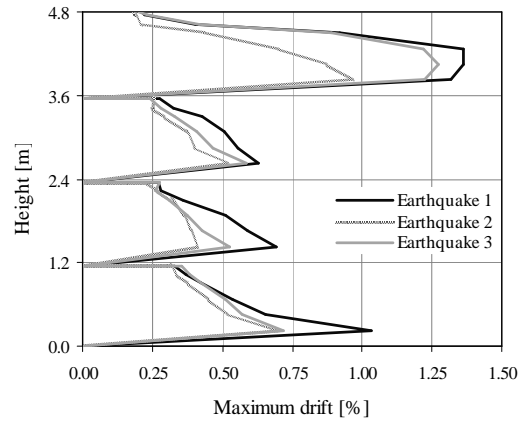

(b)

FIGURE 7. Results in the section $L 1$ according to the facade orthogonal direction: (a) maximum displacement; (b) maximum drift.

Concerning to the evaluation of the behavior at the structure base, it was defined, along the time, the relation between the load factor, $\lambda$, (Equation 3 ) and the displacement at the top of structure. The contours of the relation referred previously, for the different earthquake and directions are presented in the Fig. 8. Thus, is verified that maximum values of $\lambda$ are 0.2 and 0.65 in the transversal and longitudinal direction, respectively.

$$
\lambda=\frac{\sum \text { horizontal forces }}{\sum \text { vertital forces }}
$$




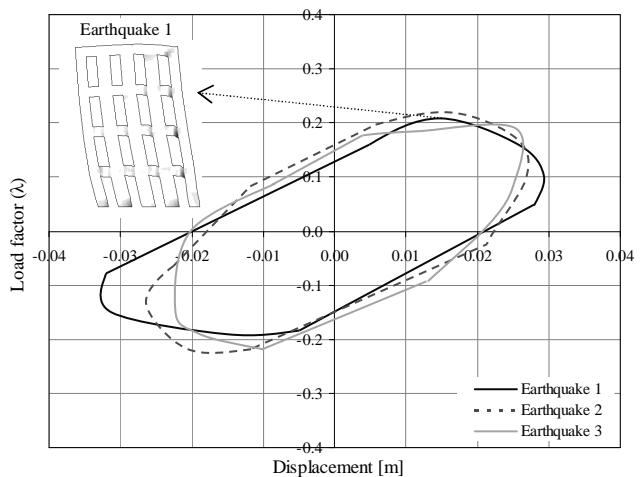

(a)

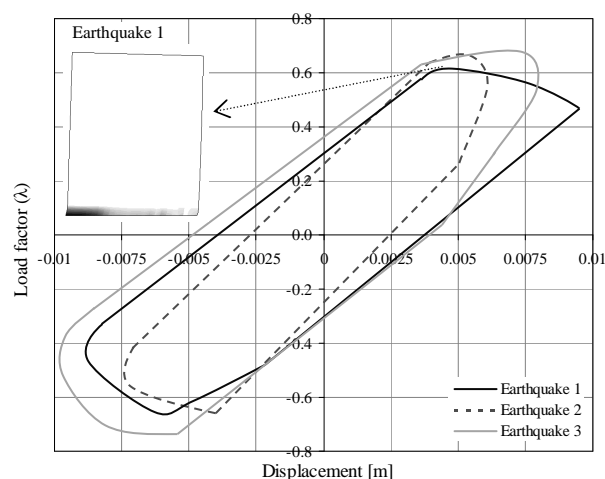

(b)

FIGURE 8. Contours of the relation displacement $\left(4^{\text {th }}\right.$ floor) $v s$. load factor (base) according the direction: (a) transversal; (b) longitudinal.

\section{PUSHOVER ANALYSES}

In alternative to the dynamic analysis were accomplished pushover analyses, which, beyond of the physical nonlinear, the geometrical nonlinear was considered. In this type of analyses the seismic action was considered through a set of horizontal loads, applied independent directions, proportional: (a) to the structure mass; (b) to the $1^{\text {st }}$ vibration mode according the direction in study.

The pushover analysis proportional to the structure mass presented a maximum load factors uppermost than dynamical analysis and the crack patterns are different from the presented in Fig. 6.

In the Fig. 9 the results of the pushover analyses proportional to the $1^{\text {st }}$ vibration mode according to the transversal and longitudinal direction are presented.
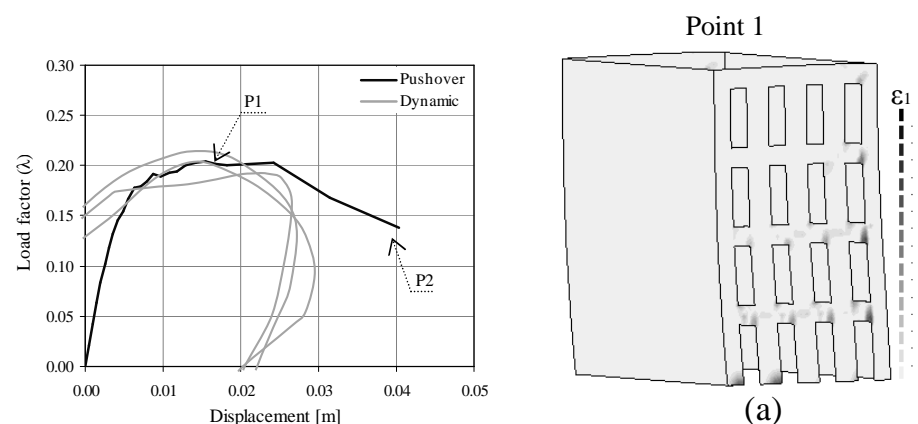

(a)

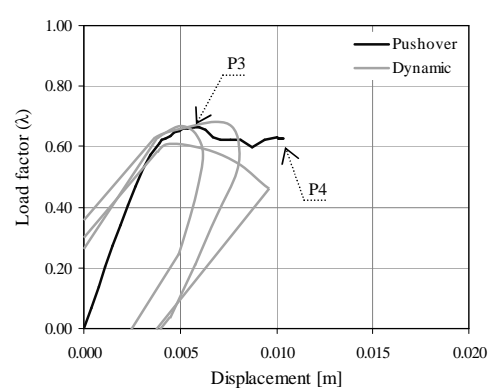

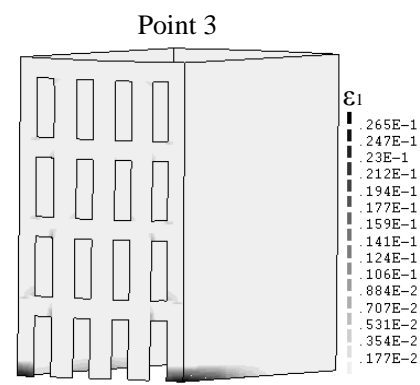

(b)
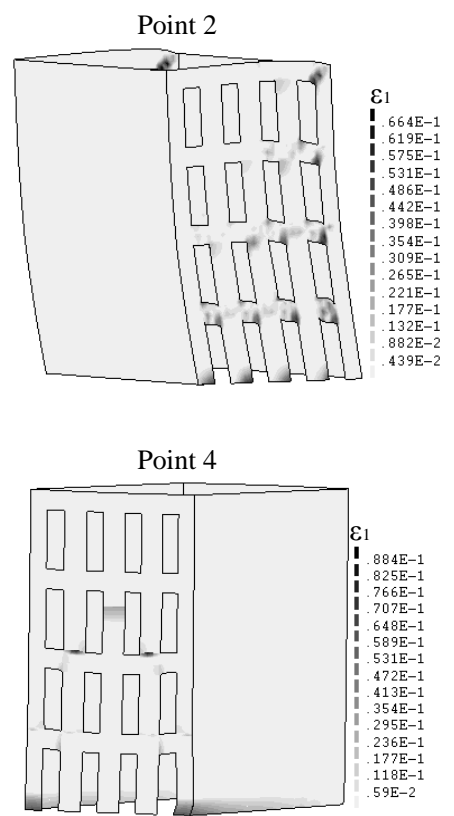

FIGURE 9. Capacity curves and tensile principal strains of the pushover analysis in the: (a) transversal direction; (b) longitudinal direction. 
Concerning the maximum load capacity, in the pushover analysis proportional to the vibration modes, is verified that the maximum load factor approaches the dynamical analysis values, what reveal that even the in the dynamical analysis the structure base is presented in their limit load capacity. However, the crack patterns only simulate correctly the damage at the lower zone of the structure (Fig. 8 and 9). Hence, the damage at the upper storeys has a significant contribution from the remaining vibration modes.

In an attempt to explore all the pushover analyses proportional to the $1^{\text {st }}$ vibration modes in the two principal directions, an adaptive pushover analysis was done, where the horizontal loads were applied simultaneously, in the relation $100 \%$ and $30 \%$ in longitudinal and transversal directions, respectively, and updated as function of the damage. However, this analysis didn't present improvements in terms of final results.

\section{CONCLUSIONS}

Through the developed study it was verified that the buildings of "gaioleiro" type with appropriate pavement-wall connection, under seismic action (Lisbon and soil of the type A) are in the limit of their load capacity for a safety factor equal to1.0, conclude that this type of buildings should be aim of seismic strengthening interventions.

Concerning the typical pushover analyses (proportional to the mass or to the $1^{\text {st }}$ mode) was concluded that these don't simulate correctly the total damage of the structure, showing that vibration modes with frequencies above the $1^{\text {st }}$ mode, in the two orthogonal directions in plant, have significant contribution for the global behavior, couldn't be depreciated.

\section{ACKNOWLEDGMENTS}

The authors are grateful to LNEC for the results obtained experimentally and to FCT (Foundation for the Science and the Technology) for the financing through the POCI/ECM/61671/2004 research project.

\section{REFERENCES}

1. F. F. S. Pinho, "Paredes de Edifícios Antigos em Portugal”, Colecções Edifícios, nº, LNEC, 2000. (in Portuguese)

2. P. Candeias, A. C. Costa, E. Coelho, "Shaking Table Tests of 1:3 Reduced Scale Models of Four Story Unreinforced Masonry Buildings", $13^{\text {th }}$ World Conference on Earthquake Engineering, Vancouver, Canada, 2004.

3. E.C. Carvalho, "Invited Lectrure: Seismic Testing of Structures", Proceedings of the $11^{\text {th }}$ European Conference on Earthquake, Paris, France. Rotterdam: AA Balkema, 1998.

4. TNO, "Displacement method ANAlyser", version 9.1, cd-rom, Netherlands.

5. M. Nuno and P. B. Lourenço, "Redução da Vulnerabilidade Sísmica de Edifícios Antigos de Alvenaria”, Relatório de Actividades, FCT, 2007. (in Portuguese)

6. EN 1998-1, "Design of Structures for Earthquake Resistance- General Rules, Seismic Actions and Rules for Buildings”, Eurocode 8, 20004. 